\section{BRAZIULIAN JOURNAL}

OF MEDICAL AND BIOLOGICAL RESFARCH

www.bjournal.com.br
ISSN 0100-879X

Volume 44 (7) 606-728 July 2011

BIOMEDICAL SCIENCES

AND

CLINICAL INVESTIGATION

Braz J Med Biol Res, July 2011, Volume 44(7) 647-651

doi: 10.1590/S0100-879X2011007500061

Effect of methylprednisolone on perivascular pulmonary edema, inflammatory infiltrate, VEGF and TGF-beta immunoexpression in the remaining lungs of rats after left pneumonectomy

F. Guimarães-Fernandes, M.N. Samano, R.P. Vieira, C.R. Carvalho, R. Pazetti, L.F.P. Moreira, P.M. Pêgo-Fernandes and F.B. Jatene

The Brazilian Journal of Medical and Biological Research is partially financed by
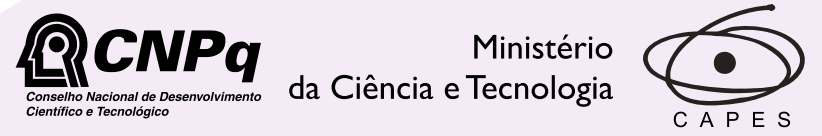

Ministério da Educação
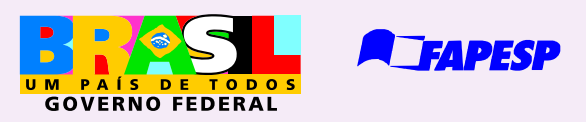

Institutional Sponsors
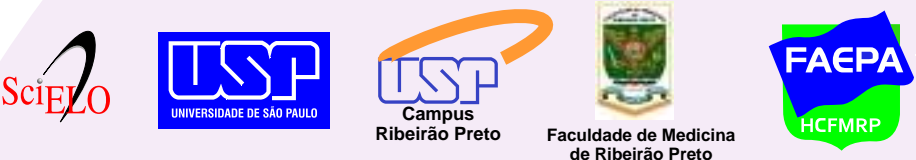


\title{
Effect of methylprednisolone on perivascular pulmonary edema, inflammatory infiltrate, VEGF and TGF-beta immunoexpression in the remaining lungs of rats after left pneumonectomy
}

F. Guimarães-Fernandes ${ }^{2}$, M.N. Samano ${ }^{2}$, R.P. Vieira ${ }^{1}$, C.R. Carvalho ${ }^{1}$, R. Pazetti², L.F.P. Moreira ${ }^{2}$, P.M. Pêgo-Fernandes ${ }^{2}$ and F.B. Jatene ${ }^{2}$

1Departamento de Clínica Médica, Faculdade de Medicina, Universidade de São Paulo, São Paulo, SP, Brasil ${ }^{2}$ Departamento de Cardiopneumologia, Instituto do Coração, Hospital das Clínicas, Faculdade de Medicina, Universidade de São Paulo, São Paulo, SP, Brasil

\begin{abstract}
Pneumonectomy is associated with high rates of morbimortality, with postpneumonectomy pulmonary edema being one of the leading causes. An intrinsic inflammatory process following the operation has been considered in its physiopathology. The use of corticosteroids is related to prevention of this edema, but no experimental data are available to support this hypothesis. We evaluated the effect of methylprednisolone on the remaining lungs of rats submitted to left pneumonectomy concerning edema and inflammatory markers. Forty male Wistar rats weighing $300 \mathrm{~g}$ underwent left pneumonectomy and were randomized to receive corticosteroids or not. Methylprednisolone at a dose of $10 \mathrm{mg} / \mathrm{kg}$ was given before the surgery. After recovery, the animals were sacrificed at 48 and $72 \mathrm{~h}$, when the $\mathrm{pO}_{2} / \mathrm{FiO}_{2}$ ratio was determined. Right lung perivascular edema was measured by the index between perivascular and vascular area and neutrophil density by manual count. Tissue expression of vascular endothelial growth factor (VEGF) and transforming growth factor-beta (TGF- $\beta$ ) were evaluated by immunohistochemistry light microscopy. There was perivascular edema formation after $72 \mathrm{~h}$ in both groups $(P=0.0031)$. No difference was observed between operated animals that received corticosteroids and those that did not concerning the $\mathrm{pO}_{2} / \mathrm{FiO}_{2}$ ratio, neutrophil density or TGF- $\beta$ expression. The tissue expression of VEGF was elevated in the animals that received methylprednisolone both 48 and $72 \mathrm{~h}$ after surgery $(P=0.0243)$. Methylprednisolone was unable to enhance gas exchange and avoid an inflammatory infiltrate and TGF- $\beta$ expression also showed that the inflammatory process was not correlated with pulmonary edema formation. However, the overexpression of VEGF in this group showed that methylprednisolone is related to this elevation.
\end{abstract}

Key words: Pneumonectomy; Glucocorticoids; Pulmonary edema; Vascular endothelial growth factor; Animal model; Transforming growth factor beta.

\section{Introduction}

The mortality of pneumonectomy is very high in comparison to other pulmonary surgical procedures, reaching up to $9.4 \%$ in some studies $(1,2)$. When compared to lobectomy, the mortality increases almost 10 -fold. Although pulmonary lobectomy is the standard surgical treatment for lung cancer, pneumonectomy is still required in some cases, such as those involving central or bulky tumors. Some other inflammatory diseases such as tuberculosis, bronchiectasis and other non-malignant diseases may also require extirpation of one lung.
Even though there have been improvements in surgical management with reduction of mortality, the incidence of complications is about $60 \%$. Respiratory complications are the most frequent, corresponding to $15 \%$. In this group of patients the mortality can reach $30 \%$. Among the most relevant complications are acute respiratory failure, pneumonia, pulmonary thromboembolism, and pulmonary edema. When pulmonary edema occurs after pneumonectomy with no association with pre-existing heart disease, acute pulmonary thromboembolism or an infectious disease it is

Correspondence: M.N. Samano, Av. Dr. Enéas C. Aguiar, 44, 2o andar, Bloco II, Sala 9, 05403-000 São Paulo, SP, Brasil.

Fax: +55-11-3069-5351. E-mail: marcos.samano@incor.usp.br

Received September 24, 2010. Accepted April 18, 2011. Available online May 13, 2011. Published July 25, 2011. 
called postpneumonectomy pulmonary edema (PPPE) (3).

The physiopathology of PPPE is not completely known and multifactorial causes seem to be involved in the development of edema. Endothelial damage and increased capillary permeability seem to be the most accepted hypothesis (4). Thus, the use of anti-inflammatory agents may prevent or alter the development of pulmonary edema. The treatment of acute lung injury/acute respiratory distress syndrome (ALI/ ARDS) with corticosteroids is well established and due to the similarity of clinical and radiologic features of these diseases, it may also play a major role in PPPE. Although some clinical reports of the use of corticosteroids to prevent PPPE have been published, there are no experimental studies that correlate corticosteroids and PPPE and explain the mechanism of this protective effect (5).

The association of transforming growth factor-beta (TGF- $\beta$ ) with the acute inflammatory process is well established as well its effect on the increase of vascular permeability in ARDS and ALI. TGF- $\beta$ belongs to the dimeric polypeptide family of growth factors and all human body cells produce and have receptors for this factor. TGF- $\beta$ is present in the initial phases of the inflammatory process in animal models and in human studies, and probably causes the development of edema due to a decrease in the number of gap junctions between epithelial cells. Thus, it is an important mediator of lung inflammation (6). The vascular endothelial growth factor (VEGF) also plays an important role in the regulation of tonus and permeability of the alveolo-capillary membrane, participating in the inflammatory process (7). Its regulation is a very complex process and depends on hypoxia, cytokines, endotoxins, and many other intracellular signs. In the lungs it is important during embryogenesis and development and is also important in the pathogenesis of emphysema and ALI.

In a previous study, we observed the formation of pulmonary perivascular edema in rats after left pneumonectomy without evidence of oxidative stress related to nitric oxide synthase or neutrophil migration (8). In the present study, we analyzed the effect of methylprednisolone on the partial $\mathrm{O}_{2}$ pressure $\left(\mathrm{pO}_{2}\right)$ /inspired $\mathrm{O}_{2}$ fraction $\left(\mathrm{FiO}_{2}\right)$ ratio, pulmonary perivascular edema, neutrophil infiltrate, and the expression of TGF- $\beta$ and VEGF in the remaining lung of rats after left pneumonectomy.

\section{Subjects and Methods}

The study was approved by the Scientific and Ethics Committee of the Instituto do Coração (InCor, protocol\#SDC 3125/08/041). Forty male Wistar rats weighing on average $300 \mathrm{~g}$ were included in the study. The animals were randomized into two groups: 20 underwent left pneumonectomy (control group) and 20 underwent left pneumonectomy after a single intraperitoneal injection of $10 \mathrm{mg} / \mathrm{kg}$ methylprednisolone (corticosteroid group). In the control group, 10 animals were sacrificed $48 \mathrm{~h}$ after pneumonectomy and 10 were sacrificed $72 \mathrm{~h}$ after the procedure. Similarly, the corticosteroid group was divided into two groups according to the time of sacrifice.

All animals were sedated and anesthetized with isoflurane (Cristália, Brazil) in an anesthetic chamber and a tracheal tube was inserted under light laryngoscopy. They were randomized to receive or not corticosteroid administered as an intraperitoneal injection of $10 \mathrm{mg} / \mathrm{kg}$ methylprednisolone sodium succinate (União Química, Brazil). The animals were ventilated in a Harvard Apparatus model 683 with a gas mixture of oxygen and isoflurane at a tidal volume of $10 \mathrm{~mL} / \mathrm{kg}$. The respiratory rate was 80 cycles per minute. Thoracotomy was performed in the fifth left intercostal space and pneumonectomy was performed with en bloc ligation of pulmonary hilum. After resection of left lung a chest tube was introduced through the incision and removed after chest closure. The animals were sent to the animal house and maintained for 48 or $72 \mathrm{~h}$ with food and water ad libitum.

At the time of sacrifice, the animals were once again sedated and intubated. After sternolaparotomy the abdominal aorta was accessed to collect an arterial blood sample for gas analysis and the animals were sacrificed by exsanguination via resection of the aorta. The lower lobe was maintained inflated with trapped air by ligation of the corresponding bronchus, fixed in buffered formaldehyde, embedded for $24 \mathrm{~h}$ and submitted to histological examination.

The $\mathrm{pO}_{2} / \mathrm{FiO}_{2}$ ratio was determined by gas analysis of an arterial blood sample collected just before sacrifice for

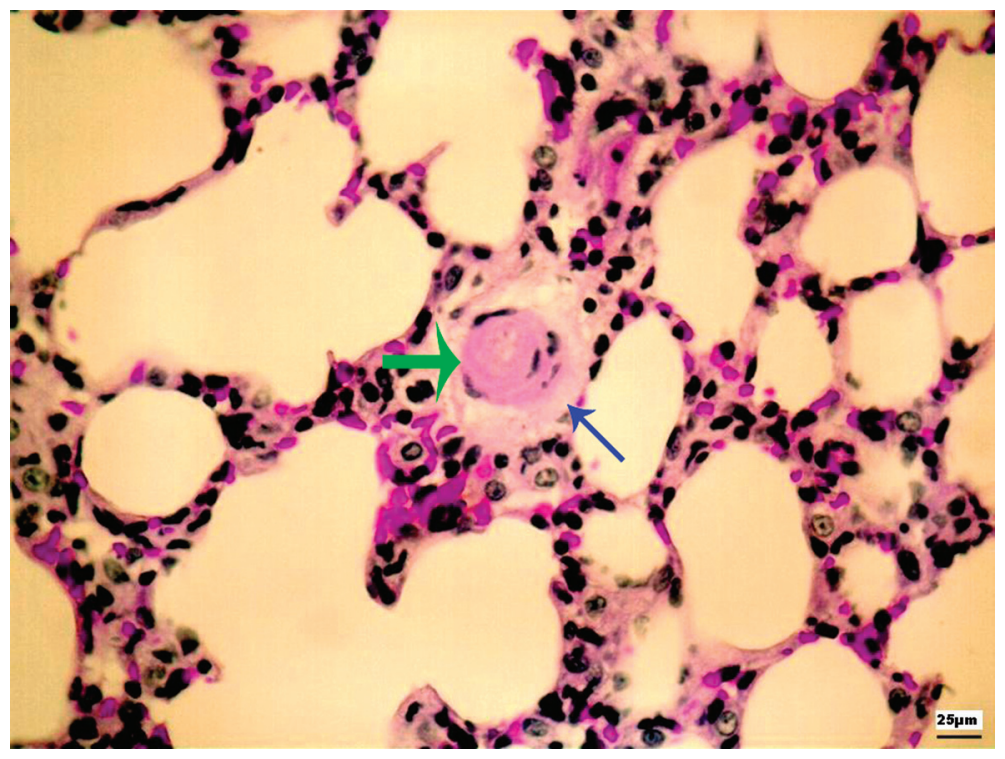

Figure 1. Digitized small-caliber vessel (green arrow) with sorrounding perivascular edema (blue arrow). The perivascular edema index is the ratio between perivascular edema and vessel area. Magnification $=400 \mathrm{X}$. 
the assessment of pulmonary function at 48 and $72 \mathrm{~h}$.

Histological sections stained with hematoxylin/eosin (HE) were analyzed in order to quantify pulmonary edema. Digitized images of parenchymal small caliber vessels were analyzed with the UTHSCSA-Image-Tool ${ }^{\circledR}$ software, version 3.0 (9). An index for semiquantitative quantification of perivascular pulmonary edema (perivascular edema index) was calculated on the basis of the relationship between the perivascular area and the vascular area (Figure 1), as described in Ref. 8.

Neutrophil density was used to quantify the inflammatory infiltrate in histological sections stained with HE. A manual count of neutrophils present in the alveolar septa was performed by an observer blind to the study. Twenty non-coincident fields, enlarged to 400X, were quantified by the point-counting technique $(8,10)$.

TGF- $\beta$ and VEGF were quantified on the basis of the immunohistochemistry in bronchial epithelial cells. The polyclonal antibodies antiTGF- $\beta$ and anti-VEGF (Santa Cruz Biotechonology Inc., USA) were used together by the biotin-streptavidin technique on lung sections. Digital quantitative analysis was performed using the Image Pro Plus 4.0 software (Media Cybernetics, USA), and expression was determined as the ratio between the positive area and the entire corresponding epithelial area in five complete airway sections from each animal (Figure 2).

Statistical analysis was performed using the GraphPad software for Windows. Data were analyzed by two-wayANOVA and complemented by the Bonferroni $t$-test. The results obtained were parametric, and the values were reported as averages with a $95 \%$ confidence interval. The level of significance was set at $5 \%$.

\section{Results}

The average $\mathrm{pO}_{2} / \mathrm{FiO}_{2}$ values for the pulmonary function of animals submitted to pneumonectomy were not significantly different from those of the animals submitted to pneumonectomy and receiving methylprednisolone at 48 or $72 \mathrm{~h}$. However, there was an increase in perivascular pulmonary edema, as shown in Figure 3, in the animals of both groups sacrificed after $72 \mathrm{~h}$ compared to $48 \mathrm{~h}(\mathrm{P}=0.0031)$.

Neutrophil density did not differ significantly between groups. However, a decrease was observed in the corticosteroid group 48 and $72 \mathrm{~h}$ after pneumonectomy. The average neutrophil density was 501.6 neutrophils $/ 10^{5} \mu \mathrm{m}^{2}$ after $48 \mathrm{~h}$ and 734.7 neutrophils $/ 10^{5} \mu \mathrm{m}^{2}$ after $72 \mathrm{~h}$ in the control group and 424.8 and 479.3 neutrophils $/ 10^{5} \mu \mathrm{m}^{2}$, respectively, in the corticosteroid group. The expression of TGF- $\beta$ also did not differ between the control and corticosteroid groups $(P=$ $0.5525)$. However, the graph in Figure 4 shows that the im-

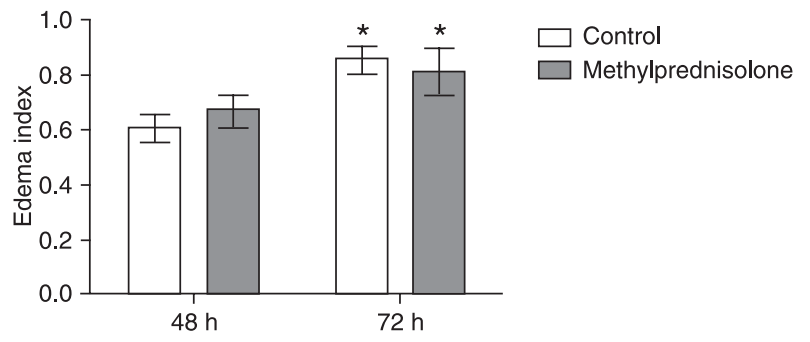

Figure 3. Pulmonary edema index graph showing edema formation $72 \mathrm{~h}$ after pneumonectomy ( ${ }^{*} \mathrm{P}=0.0031$ ), without distinction between the control and corticosteroid groups. Data are reported as means \pm SEM for 10 animals in each group (two-way ANOVA, complemented by the Bonferroni $t$-test).

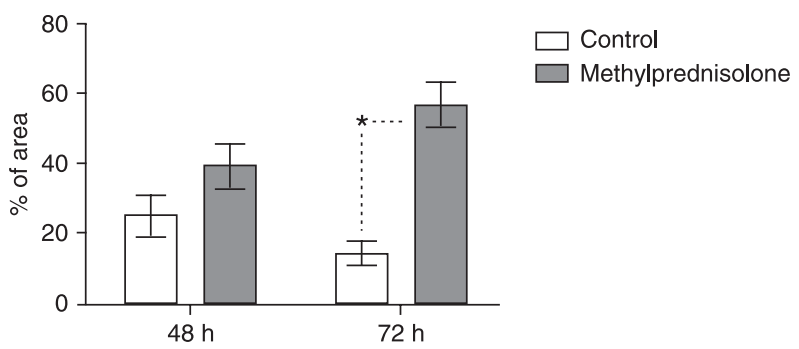

Figure 4. Vascular endothelial growth factor showing a statistically significant increase of immunohistochemical expression after corticosteroid $\left({ }^{*} P<0.001\right)$. Data are reported as means \pm SEM for 10 animals in each group (two-way ANOVA, complemented by the Bonferroni $t$-test). 
munohistochemical expression of VEGF was significantly increased in the corticosteroid group $72 \mathrm{~h}$ after pneumonectomy $(P<0.001)$.

\section{Discussion}

The hemodynamic and pulmonary physiological changes occurring after pneumonectomy have not been fully determined. The contribution of the right lung to the total pulmonary capacity is about 53 to $55 \%$, and that of the left lung is 45 to $47 \%$. In rats, the left lung corresponds to only $35 \%$ of total pulmonary mass (11). Pulmonary function declines in all patients who undergo pneumonectomy and depends on the side of the procedure, patient age and the remaining lung function. The forced vital capacity (FVC) and the forced expiratory volume in the first second (FEV1) decline to less than $50 \%$ of the initial values. Usually there is no alteration in oxygen saturation, $\mathrm{pO}_{2}$ or $\mathrm{pCO}_{2}$, but oxygen consumption is reduced from 17 to $28 \%$ after pulmonary resection (2). In the present experimental model, as described before, the $\mathrm{pO}_{2} / \mathrm{FiO}_{2}$ ratio showed absence of functional loss after pneumonectomy. Similarly, the administration of corticosteroid before the operation did not improve the levels of $\mathrm{pO}_{2}$ after pneumonectomy (8).

The perivascular space of rodents is formed by capillaries and connective tissue. During inflammatory processes or allergic reactions this space can be infiltrated by leukocytes. The importance of this space has been long neglected due to the studies focused on other pulmonary compartments such as the interstice, bronchoalveolar space and basement membrane of the bronchi. However, it is well known now that the perivascular space is related to the extravascular lung water accumulation that occurs in pulmonary edema (12-15). In an experimental model of asthma, there is rapid migration of eosinophils to this space (16). In the present study, pneumonectomy caused perivascular pulmonary edema in the group sacrificed after $72 \mathrm{~h}$, which was not affected by corticosteroid administration. This is evidence that pulmonary edema occurs as a result of pneumonectomy and that the administration of an anti-inflammatory agent has no protective effect on edema formation.

The association of pulmonary edema and acute inflammation is evident in ALI/ARDS, where neutrophils play an important role in endothelial injury and vascular permeability. Although a surgical procedure can trigger an inflammatory

\section{References}

1. Bernard A, Deschamps C, Allen MS, Miller DL, Trastek VF, Jenkins GD, et al. Pneumonectomy for malignant disease: factors affecting early morbidity and mortality. $J$ Thorac Cardiovasc Surg 2001; 121: 1076-1082.

2. Kopec SE, Irwin RS, Umali-Torres CB, Balikian JP, Conlan AA. The postpneumonectomy state. Chest 1998; 114: 1158-1184. process, the neutrophil infiltrate is reduced 48 and $72 \mathrm{~h}$ after pneumonectomy (8). Despite the well-known effect of corticosteroid on neutrophil migration, we observed only a trend to a reduction of the neutrophil infiltrate after corticosteroid administration, which was not statistically significant.

TGF- $\beta$ has been shown to be related to edema formation in animal and human studies. There is an increase of its expression after the induction of ARDS with tracheal instillation of Escherichia coli toxin. The importance of TGF- $\beta$ in pulmonary edema formation has been observed in another study in which TGF- $\beta$ knock-out animals showed lower pulmonary edema formation compared to normal animals (17). There is a relationship between TGF- $\beta$ expression and ARDS in humans, where its expression is increased in the initial phases of ARDS and its higher concentration is related to a worse $\mathrm{pO}_{2} / \mathrm{FiO}_{2}$ ratio. There is a lack of studies concerning analyses of TGF- $\beta$ expression after surgical procedures. It is reasonable to assume that surgery may act as a trauma and elevate the expression of inflammatory markers. However, we did not observe an effect of corticosteroid on the immunoexpression of TGF- $\beta$ after pneumonectomy.

VEGF is a protein that regulates endothelial cell differentiation and angiogenesis, which was discovered as a vascular permeability factor (18). In humans, most studies on lung injuries have shown a reduction of intrapulmonary VEGF levels in ALI/ARDS, especially in the early stages (19). However, several in vitro studies revealed that VEGF increases the endothelial permeability $(20,21)$. In fact, there are few studies concerning VEGF and its effect on pulmonary edema. In the present study, we observed that corticosteroid caused increased expression of VEGF but without a correlation with pulmonary edema formation. Although there is no consensus about the real effect of VEGF, an anti-inflammatory action was observed in the present study.

Pneumonectomy caused perivascular pulmonary edema $72 \mathrm{~h}$ after the procedure and corticosteroid did not prevent this edema. We did not observe an anti-inflammatory action of corticosteroid concerning the neutrophil infiltrate or TGF- $\beta$ expression. This finding supports the idea that perivascular edema formation occurs after pneumonectomy and is not related to inflammatory involvement. Methylprednisolone was responsible for an increase in VEGF levels after pneumonectomy.
3. Parquin F, Marchal M, Mehiri S, Herve P, Lescot B. Postpneumonectomy pulmonary edema: analysis and risk factors. Eur J Cardiothorac Surg 1996; 10: 929-932.

4. Deslauriers J, Aucoin A, Gregoire J. Postpneumonectomy pulmonary edema. Chest Surg Clin N Am 1998; 8: 611-31, ix.

5. Cerfolio RJ, Bryant AS, Thurber JS, Bass CS, Lell WA, 
Bartolucci AA. Intraoperative solumedrol helps prevent postpneumonectomy pulmonary edema. Ann Thorac Surg 2003; 76: 1029-1033.

6. Dhainaut JF, Charpentier J, Chiche JD. Transforming growth factor-beta: a mediator of cell regulation in acute respiratory distress syndrome. Crit Care Med 2003; 31: S258-S264.

7. Lahm T, Crisostomo PR, Markel TA, Wang M, Lillemoe KD, Meldrum DR. The critical role of vascular endothelial growth factor in pulmonary vascular remodeling after lung injury. Shock 2007; 28: 4-14.

8. Samano MN, Pazetti R, Prado CM, Tiberio IC, Saldiva PH, Moreira LF, et al. Effects of pneumonectomy on nitric oxide synthase expression and perivascular edema in the remaining lung of rats. Braz J Med Biol Res 2009; 42: 1113-1118.

9. Monteiro RJ, Jatene FB, Pazetti R, Correia AT, Manoel LA, Bernardo WM, et al. Evaluation of the cardiac morphological alterations secondary to the pulmonary emphysema: experimental study in rats. Braz J Cardiovasc Surg 2004; 19: 341-347.

10. Finkelstein R, Fraser RS, Ghezzo H, Cosio MG. Alveolar inflammation and its relation to emphysema in smokers. Am J Respir Crit Care Med 1995; 152: 1666-1672.

11. Brown LM, Rannels SR, Rannels DE. Implications of postpneumonectomy compensatory lung growth in pulmonary physiology and disease. Respir Res 2001; 2: 340-347.

12. Drake RE, Laine GA, Allen SJ, Katz J, Gabel JC. A model of the lung interstitial-lymphatic system. Microvasc Res 1987; 34: 96-107.

13. Nagai H, Kira S, Mimoto T, Inatomi K, Yoneda R. Sequential changes of perivascular edema cuffs in models of perme- ability and hemodynamic pulmonary edema. Respiration 1991; 58: 57-61.

14. Pabst R, Tschernig T. Perivascular capillaries in the lung: an important but neglected vascular bed in immune reactions? J Allergy Clin Immunol 2002; 110: 209-214.

15. Schmiedl A, Tschernig T, Luhrmann A, Pabst R. Leukocyte infiltration of the periarterial space of the lung after allergen provocation in a rat asthma model. Pathobiology 2005; 72 : 308-315.

16. Pabst R. The periarterial space in the lung: its important role in lung edema, transplantation, and microbial or allergic inflammation. Pathobiology 2004; 71: 287-294.

17. Pittet JF, Griffiths MJ, Geiser T, Kaminski N, Dalton SL, Huang $X$, et al. TGF-beta is a critical mediator of acute lung injury. J Clin Invest 2001; 107: 1537-1544.

18. Lahm T, Crisostomo PR, Markel TA, Wang M, Lillemoe KD, Meldrum DR. The critical role of vascular endothelial growth factor in pulmonary vascular remodeling after lung injury. Shock 2007; 28: 4-14.

19. Kosmidou I, Karmpaliotis D, Kirtane AJ, Barron HV, Gibson $\mathrm{CM}$. Vascular endothelial growth factors in pulmonary edema: an update. J Thromb Thrombolysis 2008; 25: 259-264.

20. Koh H, Tasaka S, Hasegawa N, Yamada W, Shimizu M, Nakamura $\mathrm{M}$, et al. Protective role of vascular endothelial growth factor in endotoxin-induced acute lung injury in mice. Respir Res 2007; 8: 60.

21. Koh H, Tasaka S, Hasegawa N, Asano K, Kotani T, Morisaki $\mathrm{H}$, et al. Vascular endothelial growth factor in epithelial lining fluid of patients with acute respiratory distress syndrome. Respirology 2008; 13: 281-284. 